\title{
Optimization of usage of the multimedia equipment
}

\author{
A.N. Zelenin*, and M.L. Jusupov \\ Ural State Agrarian University, Yekaterinburg, Russia
}

\begin{abstract}
The occupations spent by means of the big screen, become more and more widespread way of training. On faculty of maintenance of transport and technological computers of faculty of transport-technological computers and tools of the Ural state agrarian university since 1996 the multimedia complex takes root into training. From the last developments it is possible to note:

*creation of a computer class of simulators-simulators of agricultural processes;

*development and implantation of interactive posters;

*development and implantation 3D computer models.

By preparation of bachelors in a direction «Agroengeniring» under the profile: «Technical systems in agrobusiness» at teaching discipline "Agricultural computers" for students 3 courses are applied the multimedia.
\end{abstract}

\section{Introduction}

The occupations spent by means of the big screen, become more and more widespread way of training.

On faculty of maintenance of transport and technological computers of faculty of transport-technological computers and tools of the Ural state agrarian university since 1996 the multimedia complex takes root into training. From the last developments it is possible to note:

* creation of a computer class of simulators-simulators of agricultural processes

* development and implantation of interactive posters

* development and implantation 3D computer models

\section{Materials and Methods}

By preparation of bachelors in a direction «Agroengeniring» under the profile: «Technical systems in agrobusiness» at teaching discipline "Agricultural computers" for students 3 courses are applied the multimedia complex consisting of following means:

*Plasma TV LG model 50PQ600R

*Notebook HP model G62

The equipment incorporated through HDMI. High Definition Multimedia Interface (HDMI plug - the interface for a multimedia of the high clearness, allowing to transfer digital

\footnotetext{
* Corresponding author: agron@mail.ru
} 
videodata of a high-resolution. However the traditional notebook is deprived possibilities of the touch panel. Therefore it was accepted to substitute solution it on iPad with an adapter on HDMI, that has enabled more creatively to approach to usage of multimedia resources.

\section{Results and Discussion}

Visibility in audiences with horizontal layout of a floor we shall define on its users. Anthopometrical database DINED [2] (Delft University of Technology - TU Delft - the Netherlands ) contains measurements of a human body in the ergonomic purposes on a site http: // dined.io.tudelft.nl/en, dined2004,302. Databases of measurements of a human body in various ergonomic poses (standing, sitting, working) are available in the open access [35].

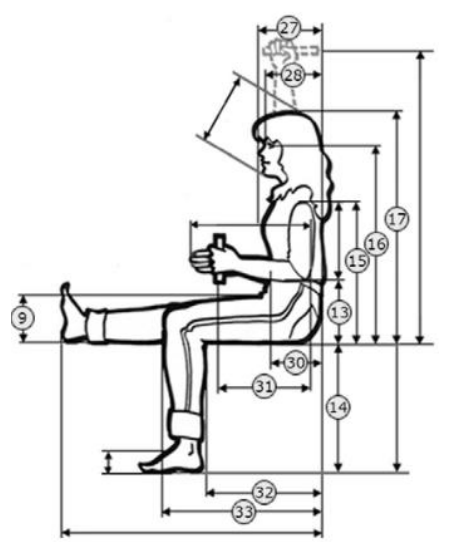

Fig.1. The Sizes of a body of the sitting person.

Source: http: // dined.io.tudelft.nl/en, dined2004,302.

To determine height of the lower side of the screen for audiences with horizontal layout of a floor we shall consider Рис.1 which shows parameters of the sitting person. For calculation of researched parameters of applied data it is used given Dr.Sci.Tech. J.F.M. (Johan) Molenbroek.

Let's concentrate on parameters at number 14, 16 and 17. Number 14 - height up to a knee bend, number 16 - a level of eyes, and number 17 - height of the sitting person. A feature team - the population of young men between 20 and 30 years of age, in other words our averaged student.

The received sizes from a database (2004) are real for $90 \%$ of such sampling.

The averaged sizes with appropriate standard deviations are taken for students man's (m) and female (f) a floor. Calculations are made in centimeters $(\mathrm{cm})$.

The Size 14 is estimated as height of sitting and has parameters

$\mathrm{m}=49.7 \pm 3.1 \mathrm{~cm}$ and $\mathrm{f}=44.1 \pm 2.5 \mathrm{~cm}$

The Size 16 is a height of layout of eyes in a sitting position and has parameters

$\mathrm{m}=84.2 \pm 3.9 \mathrm{~cm}$ and $\mathrm{f}=77.9 \pm 3.2 \mathrm{~cm}$

The Size 17 is a height of the person in a sitting position and has parameters

$\mathrm{m}=95.7 \pm 3.9 \mathrm{~cm}$ and $\mathrm{f}=88.8 \pm 3.2 \mathrm{~cm}$

The average sizes can be incorporated to determine the averaged height of eyes (the sum of the sizes 14 and 16) or the averaged height of the person (number 14 and 17):

$$
\bar{X}_{3}=\bar{X}_{1}+\bar{X}_{2} .
$$


When the average sizes are summarized, appropriate standard deviations sd1 and sd2 should be squared and added the double coefficient of correlation for the corresponding size. The square root receives the corrected standard deviation $\mathrm{sd} 3$ for the appropriate sizes:

$$
\mathrm{sd}_{3}=\sqrt{\mathrm{sd}_{1}^{2}+\mathrm{sd}_{2}^{2} \pm 2 * \mathrm{r}^{*} \mathrm{sd}_{1}^{*} \mathrm{sd}_{2}}
$$

With a coefficient of correlation $r=0.65$.

$\mathrm{R}$ value is defined on website DINED and used to unite the sizes.

As a result height of a level of an eye for students - men

$133.9 \pm 6.3 \mathrm{~cm}$

This result - with normal allocation of a variable, as shown in a figure 3 that means, that $133.9 \pm 6.3 \mathrm{~cm}$ makes $90 \%$ of sampling of a population. This height of a level of eyes is between 5-th and 95-th percent.

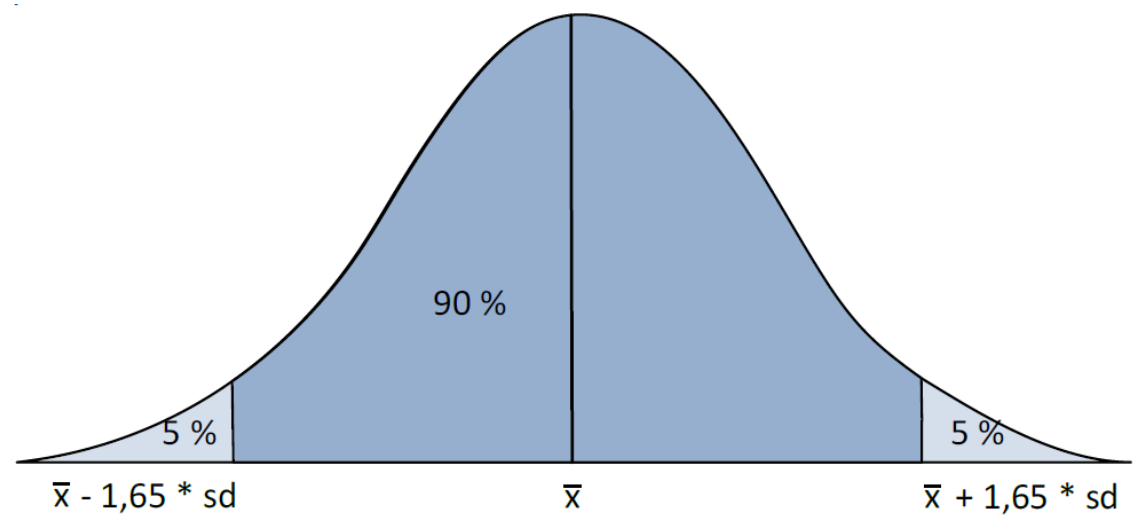

Fig. 2. Normal allocation with P5 and P95.

The distance from average X up to 5 percent (P5) or up to 95 percent (P95) at a standard deviation $1.65 *$ sd means, that for students-male height of a level of eyes

$\mathrm{P} 5=133.9-1.65 * 6.3=123.5 \mathrm{~cm}$ and

$\mathrm{P} 95=133.9+1.65 * 6.3=144.3 \mathrm{~cm}$

Height of the sitting person for students - men $145.4 \pm 6.3 \mathrm{~cm}$ that means

$\mathrm{P} 5=145.4-1.65 * 6.3=135.0 \mathrm{~cm}$ and

$\mathrm{P} 95=145.4+1.65 * 6.3=155.8 \mathrm{~cm}$

Height of a level of an еуе for студенток $-122.0 \pm 5.2 \mathrm{~cm}$

Their appropriate parameters will be

P5 $=122.0-1.65 * 5.2=113.4 \mathrm{~cm}$ and

$\mathrm{P} 95=122.0+1.65 * 5.2=130.6 \mathrm{~cm}$

At last, the height of the sitting person for student-female will be $132.9 \pm 5.6 \mathrm{~cm}$ that means

$\mathrm{P} 5=132.9-1.65 * 5.6=123.7 \mathrm{~cm}$ and

$\mathrm{P} 95=132.9+1.65 * 5.6=142.1 \mathrm{~cm}$

In audiences students usually sit next to horizontal layout of a floor with each other, and as the friend behind of the friend. Depending on position of the demonstration screen the majority of students should move sideways from each other to watch the information presented on the screen. Installation of the screen in the appropriate height received from вышеупомянутых of parameters, can prevent such situations. Its height for students can vary between the minimum height approximately $130 \mathrm{~cm}$ up to a maximum approximately 
in $155 \mathrm{~cm}$ Height layout of the lower edge of the screen of $140 \mathrm{~cm}$ approaches in most cases.

Output - distance up to the lower edge of the screen should make $140 \mathrm{~cm}$ above a level of a floor.

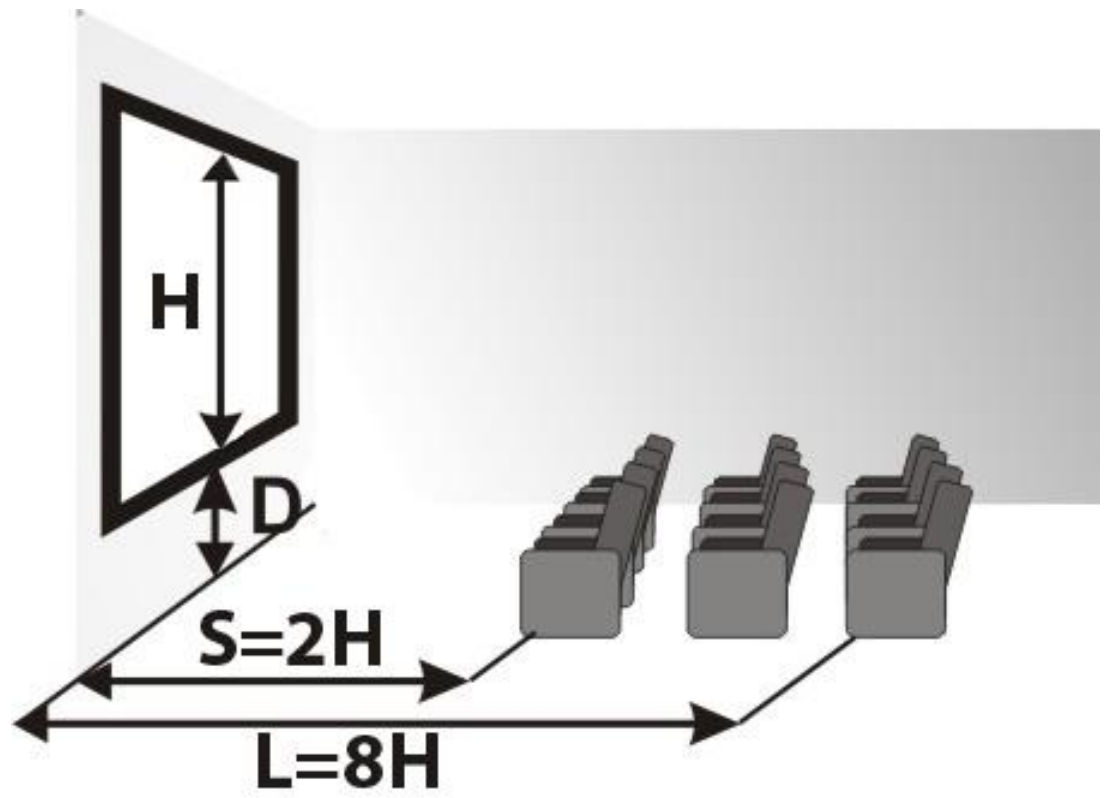

Fig. 3. Parameters of layout of the screen.

Such data are joined to the standard guidelines. For example, company Classic Solution - the German company making projectional screens already more of 10 years, on the site (http: //, screens.classic-solution.ru/service/choice.php) informs - «If a floor in horizontal (i.e. not oblique, as in a cinema) the lower edge of the screen should is on distance of 1-1,5 meters from a floor (distance D in a figure 3) » [1-3].

For observance of such parameters it is not enough to allocate the screen monitor with the big diagonal simply on desktop. It will be allocated too low and back numbers of students in an audience will acquire is much worse the information. Therefore it was accepted to install solution in a specialized audience of 3212 faculties of maintenance of transport and technological computers plasma TV LG model 50PQ600R on a special rack with the regulated height of layout of the TV. After that students have ceased to rise, pull necks and to ask again the lecturer during occupation and all audience the information going from the demonstration screen became accessible. Thus, having optimized height of layout of the screen monitor, we have received better mastering knowledge [6-8]. 


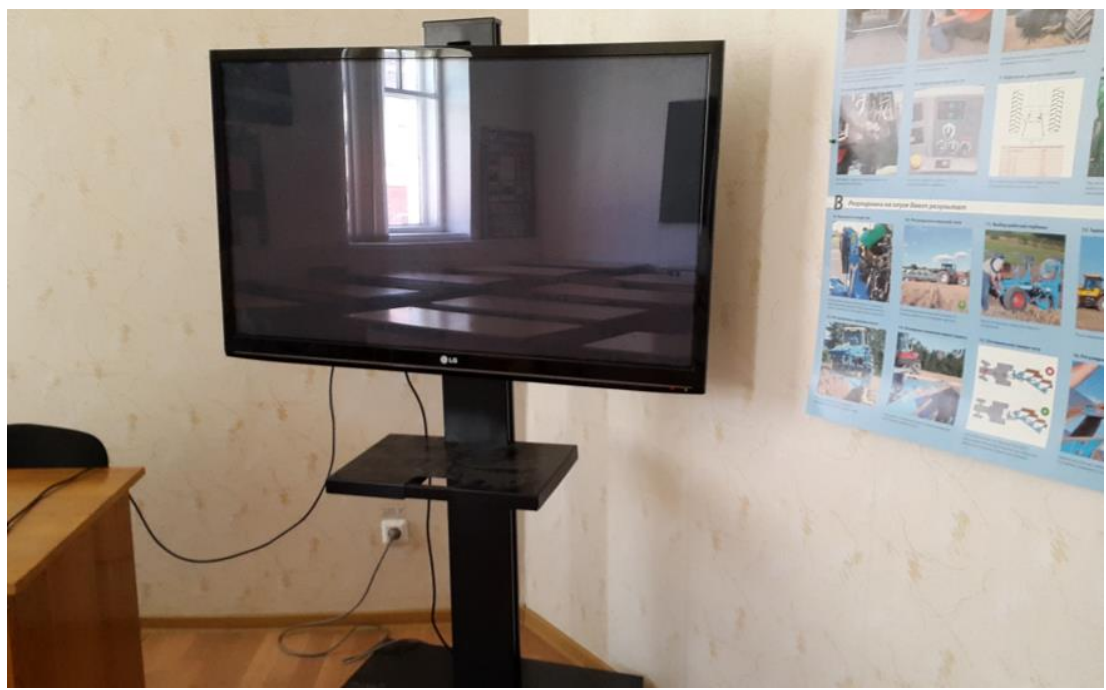

Fig. 4. Optimization of height of layout of the screen monitor in room \#3212.

\section{Conclusion}

As additional organizational actions it is possible to recommend the following: the browse will be better, if lower students will sit ahead of an audience, and higher students will take a place in back numbers.

For modern professional creation teachers need to acquire that one of fundamental conditions in the given process belongs to creative possibilities, which it is necessary not only to develop but as in every possible way to encourage them during training in HIGH SCHOOL for students.

All situations and techniques of manifestation of creative abilities of students will be possible only at the non-standard ratio of teachers to the given problem, otherwise process of preparation for such occupations much more difficultly also takes away more time. Therefore it is necessary to realize, that those agroengineers which we today release from agrarian university, will shortly define the future development of our state, and that, how much fast and effectively they will solve the professional tasks, depends on quality of the received derivation and a level of development of their creative abilities.

\section{References}

1. Gaziziva, The electronic journal, 7, 8 (2008) http: // www.meli.ru/cmagazinc/vipusk 7.htm

2. Anthopometrical database DINED (Delft University of Technology, TU Delft, the Netherlands) http: //, dined.io.tudelft.nl/en, dined2004,302.

3. Dr. ing. A.H.W. (Piet) van der Zanden, Delft University of Technology, Netherlands http://, homepage.tudelft.nl/9c41c/Readability_in_classrooms.pdf/

4. Classic Solution, http: //, screens.classic-solution. Ru/service/choice.php

5. A.N. Zelenin, M.L. Jusupov, To a question of teaching of discipline « Agricultural computers $\gg$ with usage of an interactive board, http: //, www.rusnauka.com/29_NPM_2014/Pedagogica/5_177915.doc.htm 
6. T.-H. Jiang, S.-L.Chen, J.K.C. Chen, Journal of Business Research, 69 (6), 2252-2258 (2016) http://www.elsevier.com/locate/jbusres doi: 10.1016/j.jbusres.2015.12.038

7. Interactive multimedia-based teaching material for 3-dimensional geometry Journal of Physics: Conference Series, $943 \quad$ (1), 012047, http://www.iop.org/EJ/journal/conf doi: 10.1088/1742-6596/943/1/012047

8. M. Armenteros, S.-S. Liaw, M.J. Sánchez-Franco, M. Fernández, R.A. Sánchez, Analysis of FIFA referees and assistant referees' motivational factors towards the Multimedia Teaching Materials Education and Information Technologies, 22 (3), 841872 (2017) http://www.kluweronline.com/issn/1360-2357 doi: 10.1007/s10639-0159460-y 